\title{
FONOLOGÍA Y ESCRITURA DE LA LENGUA DE SIGNOS ESPAÑOLA
}

\author{
ÁNGEL HERRERO Y JUAN JOSÉ ALFARO \\ (Universidad de Alicante)
}

\begin{abstract}
Our aim in this article is to deepen in our understanding of the phonology of Spanish Sign Language. To this end, we have taken a notion of syllable which is consonant with that of oral languages, in which hand configurations are regarded as the syllabic nucleus. We have also tried to systematize the phonemes of Spanish Sign Language by distinguishing between phoneme and allophone and by offering a few examples of the way in which phonological rules work. The result has been the possibility of creating, developing and testing a writing system based on the alphabet.
\end{abstract}

\section{Introducción}

En el estudio general de la gramática de una lengua, en nuestro caso el de la lengua de signos española (LSE), un aspecto básico lo constituye sin duda el de su estructura articulatoria elemental. En la lingüística de las lenguas de signos (LSs) se comenzó por denominar a esta estructura querológica (Stokoe 1960) pero hoy preferimos llamarla, por las razones que enseguida diremos, s-fonológica, o simplemente estructura fonológica de las LSs. La fonología de las LSs ha venido despertando en los últimos años un interés creciente en la investigación lingüística (Liddell y Johnson 1989; Wilbur 1990; Hulst 1993; Brentari 1998), también en España (Rodríguez 1992; Muñoz 1999). Nuestro propósito es avanzar en la sistematización de la estructura fonológica de la LSE.

Persiguiendo este objetivo, nos hemos encontrado con un resultado en cierto modo inesperado: la posibilidad de escribir la LSE (y de hacerlo en alfabeto romano). Decimos que inesperado sólo en cierto modo porque toda escritura conocida ha sido siempre el resultado de un análisis fonológico que explicitó — de 
forma al menos aproximada - la estructura fonológica de una lengua reproduciendo el procesamiento que llevan a cabo -inconscientemente- los propios hablantes, y porque es a todas luces evidente la conveniencia de una escritura fácilmente procesable de las LSs, conveniencia que la comunicación electrónica hace aún más urgente y que nunca podrá ser sustituida por la comunicación cara a cara (ni siquiera en su versión también electrónica).

La formulación de la estructura s-fonológica de una lengua de signos y de su escritura presupone varias decisiones previas:

1) Que si las lenguas de signos (LSs) son verdaderas lenguas, productos naturales de la facultad humana del lenguaje, entonces su estructura, también la fonológica, debe ser congruente con la que poseen todas las lenguas conocidas, orales (LOs), hasta el punto de modificar nuestra concepción demasiado material (sensorial) de éstas últimas (Hulst 1993). Basándonos en esta condición o principio de congruencia, ofreceremos el sistema de primitivos y reglas de la LSE (que podemos llamar, abreviadamente, s-fonemas y reglas s-fonológicas).

2) Que la formulación de estos primitivos y reglas, en la misma medida en que se proponen como elementos de la competencia lingüística de los signantes, debe hacerse partiendo de la realización de los signos, del «signar trabado», parafraseando a W. von Humboldt, de la articulación efectiva cuya mínima unidad llamaremos s-sílaba y reúne simultaneidad y sucesión.

c) Que la escritura lineal de los s-fonemas de la LSE en su organización articulatoria (silábica) implica una relación de orden entre los mismos, orden que debemos especificar y que debe reproducir la economía del procesamiento por parte de los propios signantes.

Tomadas estas decisiones, hay que observar desde este momento que, aunque la propuesta que aquí hacemos puede considerarse bastante avanzada (y adaptada a las sugerencias de su propia enseñanza), la escritura de más y más palabras en el marco de sus relaciones sintácticas y discursivas llevará a tomar aún decisiones particulares, ya sea en cuanto a la elección de los representamina gráficos como en cuanto a las reglas de simplificación. En ese sentido toda sugerencia de los lectores de este trabajo será muy valiosa.

En los ámbitos europeos de estudio de las lenguas de signos se han venido manejando dos sistemas de transcripción, que ya tienen programas informatizados: el HamNoSys, ideado por Siegmund Prillwitz y su grupo de la Universidad de Hamburgo (Prillwitz 1991), y el Sign Writing, ideado por Valerie Sutton en la Universidad de San Diego, California (Sutton 1995). El primero es un sistema de transcripción fonética muy analítico que se emplea habitualmente en la investigación y que no aspira a convertirse en escritura; el segundo sí está intentando extenderse como escritura, pero su carácter figurativo y no lineal hace costoso el procesamiento por ordenador. El Sing Writing, que llevamos empleando 
hace ya dos años, nos mostró la posibilidad misma de la escritura de las LSs, y es ya una contribución irreversible a la escritura de lenguas de signos. Con todo, como escrituras ambos sistemas adolecen de exceso (Pinedo 1989): quieren representar todas las configuraciones, todos los movimientos, etc., efectivamente posibles, con lo que aportan un número elevadísimo de símbolos que no representan, en cambio, el sistema interno de las lenguas de signos, sistema basado en la economía. De este mismo «defecto del exceso» adolece el sistema primero ortográfico y luego simbólico SingFont, ideado por Don Newkirk, que representa sus numerosos símbolos en varios niveles lineales, como un pentagrama, de valor figurativo pero no fonológico -aunque como el SingWriting pueda representarlo prácticamente todo.

Nuestra propuesta avanza —o esa es su intención- en el sentido lingüístico de la escritura: reduce símbolos gracias a la diferencia fundamental entre s-fonema y variante; propone un orden en la escritura (basado en la estructura silábica) y resulta congruente con la escritura del resto de las lenguas. La utilización del alfabeto es una mera convención que tiene el beneficio de su familiaridad; pues una letra (la $m$, la $a$, la $j \ldots$ ) como las que estamos todos perfectamente acostumbrados a reconocer bajo distintos tipos, ni es icónica (no representa la forma de articular la boca, aunque alguna vez lo hiciera) ni siquiera representa sonidos particulares. En el castellano, por ejemplo, no se representan de forma específica la t sonora, ni la b fricativa, ni la a larga o la nasalizada, a pesar de que estos sonidos los pronunciamos y con frecuencia. Pero no son distintivos.

$\mathrm{Al}$ emplear símbolos alfabéticos para representar la articulación de la s-sílaba, símbolos de lo que en las LOs llamamos vocales y consonantes, no estamos pensando, naturalmente, en una analogía exacta entre los elementos articulatorios de las LSs y los de las LOs. Esta analogía es innecesaria, si no perniciosa (Wilbur 1990: 89). Pero la autonomía articulatoria de las configuraciones manuales en las LSs y de las vocales en las LOs, o la dependencia de los lugares, movimientos y formas de movimiento en las primeras y de las consonantes en las segundas, permite desde nuestro punto de vista la aplicación de los mismos criterios silábicos de escritura

Por otro lado, la convención alfabética, como cualquier otra que fuera efectivamente fonológica, no puede entenderse si se sigue manteniendo que la escritura es un calco de la expresión, sea oral o signada. No lo fue ni lo podrá ser nunca, y ese límite es no sólo la base de su valor, de su universalidad y su profusión, sino que afecta incluso al tipo de registro: en la escritura no sólo nos limitamos a representar los aspectos lingüísticamente distintivos de la expresión, sino que ésta pasa a ser discurso y a sustituir elementos extralingǘsticos o poco sistemáticos (como el gesto facial o el recurso a la deixis ostensiva, ad oculos) por elementos que empiezan a ser característicamente escriturales o letrados, y que 
afectan tanto a la fonología como a la morfología y, definitivamente, a la sintaxis. La escritura, la alfabetización, transforma el nivel de lengua de forma característica y distinta a la del registro analfabeto (Givón 1999). Ese registro es desconocido en la LSE (si no en todas las LSs del mundo). Una de las decisiones que hemos tomado en este sentido, y en esta primera etapa de escritura del léxico, es la de seleccionar ejemplos que no sean estrictamente dialectales ni diatópicamente restringidos. Esperamos que el vocabulario que aparece en el Anexo sea un vocabulario si no siempre de uso al menos comprensible por la mayor parte de los signantes españoles.

La escritura tiene éxito si refleja el procesamiento de la lengua, sus primitivos y combinaciones fonológicas. Lo importante es que el análisis de sistema sfonológico sea suficientemente correcto.

\section{Fonología, s-fonología, escritura}

La fonología, al descubrir que bajo las variadas manifestaciones del sonido lingüístico el hablante abducía (reducía) una entidades abstractas o primitivos, los fonemas, en sí inmateriales o puramente distintivas, de número mucho más reducido que el de sonidos acústicamente distintos, organizadas en oposiciones sistemáticas y económicas y sometidas a ciertas reglas de combinación, dio a la linguística del siglo el rango de ciencia. Ese sistema de primitivos, junto al de sus reglas, se descubrió como fundamental en el procesamiento del lenguaje, explicaba la fonología de todas las lenguas y revelaba en ellas un parentesco fundamental.

Podría decirse que el sonido linguístico, que se procesa como fonema aunque admita realizaciones varias, es en cierto modo la cancelación del sonido en bruto, pues supone el control de este sonido instintivo. De este control neurológico que funda el lenguaje el silencio intencional guarda seguramente la huella primitiva: controlar el ruido para mantener silencio fue seguramente la primera forma de control neurológico del sonido. Si esto es así, podemos entender que, paradójica pero efectivamente, el lenguaje oral permite no oír -el resto de sonidos no lingüísticos-, abstraerlos para concentrarse en lo pertinente lingüísticamente, en los fonemas. El silencio de la escritura reproduce esta virtualidad que funda el lenguaje. Algo similar sucede en las LSs.

Parece lógico que al reconocer el valor de lenguas de las LSs nos preguntemos por este dominio de primitivos abstractos de la articulación del lenguaje, tan conocido en las LOs y tan esencial en nuestro concepto de lengua. Pero para hacerlo nada mejor que subrayar el hecho fundamental en la lingüística de que esos primitivos son efectivamente entidades teóricas, abstractas, femas peirceanos que pueden expresarse en el hombre en voz laríngea y en voz raquídea (como señaló 
Benveniste); y el hecho no menos relevante de que todas las escrituras conocidas han representado estados precientíficos pero ya teóricos de este conocimiento fonológico, propuestas de primitivos que midieron en cada caso su rigor con su éxito didáctico, con su difusión.

Es muy significativo que la aparición en la escena linguística de las LSs, a mediados de los años 60 , coincida con el triunfo en la misma escena lingüística del paradigma generativo, formulado como estudio explícitamente científico de los hechos lingüísticos que busca la estructura universal de la competencia lingüística humana. Esta confluencia será explícitamente formulada en 1995 por Noam Chomsky afirmando que «aunque altamente especializada, la facultad del lenguaje no está atada a ninguna modalidad sensorial específica, contrariamente a lo que se suponía no hace tanto. Así, el lenguaje de señas de los sordos es muy parecido estructuralmente al lenguaje hablado, y su proceso de adquisición muy similar» (Chomsky 1995, 1998: 178).

Pero esta afirmación es muy reciente. A finales de los 50 y en los sesenta la congruencia de la lingüística del signo con la linguística general en ese dominio precisamente el más científico y universal de la lingüística, en el de la fonología, todavía no se acababa de reconocer, como muestra el recurso de los primeros trabajos de signolingüística a categorías no definidas científicamente o no universales. Nos referimos a nociones como las de parámetro (Stokoe 1960) o familia de configuraciones. Su falta de congruencia con las rigurosas nociones de la lingüística de las LOs producía el sentimiento de que no estar ante una verdadera lengua.

Los conceptos femológicos claves de la fonología son los de primitivos o unidades (rasgo fonológico, fonema, alófono y sílaba), y reglas fonológicas (de combinación y de variación). Estos conceptos se refieren a fenómenos de articulación que debemos ver, como venimos repitiendo, en su carácter abstracto y general. Y es que de todos los rasgos posibles de la articulación (sean rasgos de la articulación espiratorio-bucal que produce la voz laríngea o de la articulación kinésico-manual que produce la voz raquídea), las lenguas hacen sólo uso sistemáticamente, esto es, para diferenciar palabras, de un conjunto muy estricto de entre una rejilla de unas pocas diferencias (sonoro/sordo, continuo/interrupto etc. en las LOs; de dedos juntos/separados o de movimiento con roce/sin roce, etc. en las LSs), las combinan en un número limitado de prototipos de realización (cuyos márgenes de variación están bastantes fijados) y les aplican un conjunto también estricto de reglas.

La competencia del hablante se basa en la capacidad de procesar esos prototipos primitivos y de reconocerlos a través de sus combinaciones y variantes.

Nuestro punto de partida, dentro de la tercera etapa de investigación reseñada por Margaret Deuchar (1987), es que los primitivos señalados (rasgo, fonema, 
variante, sílaba) se emplean también en el procesamiento de las LSs; y que el rasgo fundamental en la clasificación de los fonemas de las LOs, el rasgo fonológico de constituir el núcleo o bien los márgenes de la sílaba como unidad de articulación, es perfectamente congruente con la diferencia en las LSs entre s-fonemas de configuración manual y el resto de parámetros. Roman Jakobson y Moris Halle, que desarrollaron el carácter abstracto de la fonología, escribían en su trabajo fundamental del 1956 (Jakobson y Halle 1974: 37) que «el esquema elemental en torno al cual se constituye todo agrupamiento de fonemas es la sílaba». En las LSs ese papel nuclear y con capacidad de autonomía silábica lo constituyen las configuraciones manuales, los queiremas (Rodríguez 1992: 171), en los que se apoyan los demás elementos fonológicos para articular signos mientras que las configuraciones, como veremos, pueden constituir signo articulado por sí mismas. La diferencia entre núcleo y márgenes en la articulación signada es fundamental para el estudio del sistema fonológico de las LSs pero también para su escritura.

Este hecho apunta contra un prejuicio aún mantenido en el tratamiento de las LSs, el de su supuesta simultaneidad (Brentari 1998). Frente al carácter simultáneo de la signación, el sonido, que acaso es más fugaz, llevaría un orden lineal (se piensa) que la escritura ha retenido. Pero aquí hay un profundo equívoco: la escritura es lineal pero lo que representa no lo es. El primitivo sílaba, como articulación mínima, muestra y hasta expresa con su misma palabra que el procesamiento linguístico no se hace de forma lineal, sino leyendo de forma global el conjunto - el ataque silábico y la coda, que se organizan en torno a un núcleo vocálico-; ni la consonante del ataque se pronuncia antes que la vocal, ni la coda es insensible a lo que la sigue. Este fenómeno es característico del lenguaje, y ha recibido distintos nombres: recursividad, procesamiento holístico, global, o procesamiento de arriba a abajo. El que la escritura simule de forma lineal esa simultaneidad es un asunto totalmente diferente, y esta diferencia, desde nuestro punto de vista, no ha sido tenida suficientemente en cuenta en las propuestas de escritura de LSs.

Algo similar sucede cuando se considera la interioridad del sonido, su carácter abstracto, frente a la exterioridad y plasticidad de la articulación manual. La articulación de los fonemas en las lenguas orales descansa en procesos tan plásticos (y seguimos empleando términos como los de vocales labializadas, altas o retraídas, sonidos tensos o flojos, etc.) como en las LSs.

Un último prejuicio, esta vez mantenido especialmente por los propios signantes, afecta especialmente a nuestra propuesta de escritura, y es que la escritura reduce la expresividad de la signación. Es un prejuicio propio de todo iletrado, que no merece más atención, pues esta reducción es precisamente la condición de la escritura, su economía, su universalidad: la escritura propone sin explicitársela al lector la expresividad que contiene, le pone en posición de 
intérprete y no de mero descodificador. La escritura, como revela su propio nombre, es también gramática, puesta en primer plano de la estructura del lenguaje. La voz que habla o signa en lo escrito no es individual sino colectiva, prototípica, y esa es precisamente la grandeza de la escritura.

\section{La estructura fonológica y la escritura de la LSE}

Los primitivos fonológicos de la LSE son rasgos s-fonológicos, s-fonemas (con sus variantes) y s-sílabas. Esta afirmación no implica (tampoco en las LOs) que la investigación del sistema de estos primitivos (empezando por el de los rasgos) esté ultimada. No lo está especialmente en cuanto a los rasgos relativos a los lugares de articulación y a las formas de movimiento. En cierto modo, tratamos estos rasgos como en la fonología articulatoria previa a Jakobson (y todavía empleada pedagógicamente): como rasgos de distinción y clasificación dentro de un continuum (labiales, dentales, alveolares, etc.; pectorales, frontales, bucales, etc). En cambio, como se verá, los rasgos relativos a las configuraciones manuales están bastante sistematizados. En todo caso, la falta de sistematización de algunos de los rasgos distintivos no empece el tratamiento sistemático de los distintos fonemas ni, menos aún, condiciona su escritura.

Los fonemas son prototipos de realización que podemos agrupar en clases naturales (por su lugar de articulación, por su forma de articulación etc.); lo mismo cabe decir de los s-fonemas; fue a estas clases a lo que se llamó de forma intuitiva parámetros: son las clases de fonemas constituidas respectivamente por las configuraciones manuales (s-fonemas Q), por las orientaciones de la mano (sfonemas $\mathrm{O}$ ), por los lugares de signación (s-fonemas L; subclasificados en lugares del cuerpo Lc, lugares frontales al signante Lf, y lugares en el lado naturalmente lateral al signante $\mathrm{Ll}$ ), por el contacto con el lugar del cuerpo (s-fonemas $\mathrm{C}$ ), por el movimiento direccional que realiza la configuración ya ubicada, ya sea este movimiento recto, curvo, puntueado, en rozamiento, etc. pero con desplazamiento ( $\mathrm{s}$-fonemas M), y por las formas de movimiento (s-fonema $\mathrm{F}$ ) con que la configuración, con $\mathrm{M}$ o sin él, cambia su Q y/o su $\mathrm{O}$ de forma prevista (abrir /cerrar, abatirse, temblar, etc.). No tenemos en cuenta, sin embargo, el parámetro de la expresión facial o propoponema, que consideramos discriminativo pero no a nivel s-fonológico primitivo, sino en la fonología del enunciado. En unos casos la expresión facial marcada (por fruncimiento de cejas, por ejemplo) viene acompañada de un contraste en la F (idea tiene como F la extensión de los dedos que empiezan enlazados, mientras que tontería, que frunce las cejas, se signa con esa F + repetición); en otros, como en el par dulceldolor, se trata de homonimias, fenómeno absolutamente común en todas las lenguas, y desambiguable por el 
contexto. En otros, en fin, se trata de un signo fonológico suprasegmental que discrimina tipos de habla o añade comentarios ilocutivos del emisor, exactamente como el tonema en las LOs, que tiene el valor semiótico de un gesto, no de un signo (Bolinger 1983). Su valor lingüístico indudable debe ser estudiado, desde nuestro punto de vista, a otro nivel, dentro de la fonología del enunciado

Pero como hemos señalado, en la estructura fonológica universal los fonemas se distinguen y clasifican según el papel que desempeñan en la sílaba como unidad de articulación. Pues bien, para distinguir y clasificar los s-fonemas y abordar el sistema s-fonológico vamos a partir, antes de tener en cuenta las clases naturales, de una clasificación basada en una noción de s-sílaba congruente en su estructura con la de las LOs, estructura que como sabemos está constituida por un núcleo (vocal o diptongo), y opcionalmente por un ataque consonántico (de una o dos consonantes normalmente) y una coda (también con una o dos consonantes). Como hemos dicho y como las escrituras revelan, este orden es más psicológico que empírico, es un orden de procesamiento. Lo empírico en bruto es el golpe de articulación.

Efectivamente, los s-fonemas de configuración o queiremas Q, como las vocales de las LOs, pueden ser articulados por sí solos, constituir sílaba y por tanto palabra, $y$, en cambio, el resto de s-fonemas necesita el soporte de un queirema: la orientación, el lugar, el contacto y el movimiento, con su dirección y su forma, necesitan ser el lugar, el contacto, la orientación, el movimiento y la forma de movimiento con que se realiza una configuración manual. Este hecho permite mantener la diferencia fonológica fundamental entre s-fonemas nucleares y sfonemas no nucleares o marginales (de los márgenes de sílaba)

$\mathrm{La}$ dependencia funcional de los s-fonemas $\mathrm{L}, \mathrm{O}, \mathrm{C}, \mathrm{M}$ y $\mathrm{F}$ respecto a los $\mathrm{Q}$ hace de aquéllos una clase, pero se trata de una clase a su vez dividida en la LSE, desde nuestro punto de vista, en dos grandes grupos: el de los s-fonemas del margen estático o, simplemente, s-fonemas estáticos ( $\mathrm{L}, \mathrm{O}$ y $\mathrm{C}$ ), que acompañan la realización del núcleo Q en signos sin cambio (Wilbur 1990) dando lugar a distintos tipos de sílaba (Q, LQ, LCQ, QO, LCQO, etc.); y el de los s-fonemas que promueven ese cambio, fonemas del margen dinámico o, simplemente, $s$-fonemas dinámicos ( $\mathrm{M}$ y F). Los movimientos $\mathrm{M}$ son de hecho cambios de un lugar $\mathrm{L}$ a otro lugar L'; las formas de movimiento $\mathrm{F}$ cambian la configuración $\mathrm{Q}$ y la orientación O.

Esta clasificación se podría manifestar en la representación escrita o bien estableciendo la diferencia entre sílaba simple y sílaba múltiple (LCQO frente a LCQO-L'Q'O, por ejemplo), o bien, adoptando una noción de sílaba breve frente a sílaba larga, siendo esta última el resultado de un rasgo fonológico ( $\mathrm{M}$ y/o F) que prolonga, modificándola, la articulación de partida, y que aconseja una representación monosilábica de coda simple frente a otra de coda larga (LCQO 
frente LCQOMF, en su expresión más amplia). Escogemos esta segunda opción porque simplifica las redundancias de la primera, porque nos parece más acorde con la articulación del signo (en donde a veces un movimiento $\mathrm{M}$ no da lugar a un $\mathrm{L}$ específico sino a una dirección, y una forma de movimiento $\mathrm{F}$ no finaliza en una $O$ determinada sino meramente proyectada, como en la $F$ tan frecuente que consiste en extender o cerrar la configuración, como en pregunta, blanco, conferencia); y, en fin, porque permite la representación diferenciada de aquellos signos compuestos en los que sí se producen cambios claramente heterosilábicos, como en piso, por ejemplo. En estos últimos sucede como en las LOS, que las sílabas son teóricamente intercambiables - siempre que se respeten las reglas de combinación y de posición, y siempre que, naturalmente, la lengua haga uso de esta operación). En todo caso, la modificación por $\mathrm{M}$ y $\mathrm{F}$ señala una clara irreversibilidad en la articulación del signo, y ofrece a las LSs un recurso morfológico fundamental, la variación final, que invita a un tipo de lengua flexiva con desinencias de tipo $\mathrm{M}$ y/o F.

El orden de representación que estamos proponiendo es por lo tanto el siguiente:

-un ataque silábico simple formado por un fonema de lugar $\mathrm{L}$, que en el caso de tratarse del cuerpo como lugar de signación admite el fonema de contacto $\mathrm{C}$. Además del cuerpo (Lc) consideramos el lugar frontal al signante (Lf) y el lugar natural con el brazo en su posición lateral (LI)

-un núcleo formado por el fonema de configuración manual $Q$

-una coda simple, breve o estática, formada por un fonema $\mathrm{O}$

-una coda dinámica, prolongadora de la sílaba, formada por $\mathrm{M}$ y $\mathrm{F}$

( $a$ cualquier $\mathrm{M}$ o $\mathrm{F}$ puede añadirse la $\mathrm{F}$ de repetición $\mathrm{b}$ ).

Sílaba breve: L C Q O

Sílaba larga: L C Q O M F

Como hemos indicado, este orden debe ser interpretado de forma no lineal si queremos que represente el orden holístico de la articulación: ni la consonante del ataque «suena» antes de que la vocal se produzca -en las LOs- ni el lugar de signación se especifica antes de que la mano se configure —en las LSs-. Pero es un orden que está motivado diagramáticamente: la escritura reproduce, como icono diagramático (en los conocidos términos de Peirce) pero no de tipo imagen (que es sin embargo la base icónica del SingWriting) sino como diagrama o esquema, el procesamiento de la articulación: el núcleo de la articulación en el centro, implicando una lectura sintética, tanto sucesiva como anticipatoria.

La elección del lugar de signación como ataque silábico se basa también en razones de procesamiento, pero además en el hecho de que los s-fonemas de lugar son los primeros que se aprenden (Juncos 1997). En el orden de la articulación lo habitual es que la elección del lugar de la signación sea lo primero, que la mano se 
dirija a ese $\mathrm{L}$ previsto (con posible contacto si $\mathrm{L}$ es el cuerpo) articulando un $\mathrm{Q}$ con una orientación $\mathrm{O}$, y que ese conjunto se pueda modificar o prolongar mediante movimiento $\mathrm{M}$ o forma interna de movimiento $\mathrm{F}$.

La posición de $\mathrm{O}$ en la coda obedece a un argumento similar: basta comparar un signo que se signa en contacto con el cuerpo en la orientación no marcada (consideraremos como tal la de palma orientada hacia el lugar de contacto) y otro que se signa con otra orientación marcada (con la palma, digamos, de canto), como sucede respectivamente con los signos de costumbre y mentira, por ejemplo, para comprender que aunque la orientación esté prevista (como lo están las consonantes de coda en LOs, por ejemplo la $\mathrm{r}$ final de los infinitivos en español), se hace explícita sólo sobre la configuración manual Q ya fijada.

Pero para que la representación escrita tenga éxito no basta con que posea iconismo diagramático, es fundamental además que posea economía. Hay que evitar representar lo redundante y lo que se presupone. Como hemos apuntado, en la LSE hay sílabas de tipo Q (como en la LOs de tipo V). ¿Es que una mano puede configurarse sin hacerlo en un lugar del espacio y sin orientación? Una mano no: un signo sí.

Distinguimos desde este momento ubicaciones y orientaciones no marcadas o naturales, que no deben representarse:

-la ubicación de los signos bimanuales simétricos (que comenzamos escribiendo con el símbolo sm), con las manos en contacto inicial (sc), alienadas (sh), etc, que tratamos al final de este trabajo, y que se signan prototípicamente en el centro del espacio frontal (Lf). El signo se representa con el símbolo bimanual correspondiente, un blanco y la $Q$ común (+O, etc.)

- la ubicación de los signos bimanuales en los que la mano pasiva se convierte en lugar de signación corporal (Lc), colocándose prototípicamente en el centro del espacio frontal. En esta ubicación no es preciso señalar el L de dicha mano pasiva (Lf: ol) El signo comienza su escritura con la s con que simbolizamos la mano pasiva, seguida de su $Q$, nueva s y su $O$, un blanco, y los fonemas pertinentes de la mano activa ( $\mathrm{QO}$, etc.)

-las ubicaciones en el Ll por distinta articulación del brazo (flexionado ab, lateral ib, etc.) si la mano está articulada en continuación natural con el brazo. El signo comienza por $\mathrm{Q}$ y sigue necesariamente con la escritura de la orientación de la mano (ma, mi, etc.), pero no es necesario escribir la ubicación Ll.

-la orientación de la mano de canto en continuidad con el brazo extendido en $\mathrm{Ll}$ (es el caso del signo de $t u ́$, que basta representarlo por el Q).

-la orientación de la mano con la palma hacia el cuerpo, cuando es éste el lugar de signación (Lc) y haya o no contacto.

-la orientación de la dactilología cuando se deletrea un nombre de una LO y la de los números cardinales. Cuando la configuración dactilológica se ha integrado 
como Q en un signo, sí suele requerir un L (M, etc.) específico, pero su O es la natural dactilológica. Desde nuestro punto de vista, esta falta de marca en la orientación indica que el signo dactilológico no es verdaderamente una configuración propia de la LS. Lo representaremos por su letra en mayúscula. A continuación, y tras el sistema de configuraciones fonológicas, señalaremos las configuraciones dactilológicas empleadas más frecuentemente para la creación de neologismos.

\section{El sistema de configuraciones $Q$. La escritura del núcleo}

Propongo tener en cuenta como fonemas nucleares de la LSE las siguientes 29 configuraciones, según los rasgos fonológicos que aparecen en el cuadro (rasgos universales, aunque cada LS emplea un conjunto limitado y otras LSs distintas a la LSE pueden emplear por tanto algunos que en la LSE no se emplean) y representarlos según las siguientes convenciones:

\section{CUADRO DE FONEMAS CONFIGURATIVOS (Q) DE LA LSE}

\begin{tabular}{|c|c|c|c|c|c|}
\hline \multicolumn{2}{|c|}{ EXTENDIDOS } & \multicolumn{2}{|c|}{ FLEXIONADOS } & \multicolumn{2}{|c|}{ CERRADOS } \\
\hline separados & juntos & separados & juntos & en contacto & enlazados \\
\hline $\begin{array}{l}- \\
\text { pulgar }\end{array}$ & $\begin{array}{l}\text { - } \\
\text { pulgar }\end{array}$ & - & $\begin{array}{l}\text { - } \\
\text { pulgar }\end{array}$ & pulgar & $\begin{array}{l}\text { - } \\
\text { pulgar }\end{array}$ \\
\hline
\end{tabular}

\begin{tabular}{|l|l|l|l|l|l|l|l|l|l|l|l|}
\hline$\ddot{0}$ & & ò & & ó & & & o'áa & & & o & a \\
\hline & & òa & & & & & o'a & ô & & & \\
\hline & & & & éá & i & & & eâ & & eä & \\
\hline & & & & íá & & & & & & iä & \\
\hline ae & e & & & áé & é & & & âe & & àé & \\
\hline aei & ei & & èì & & éí & & & & & äei & \\
\hline au & u & & & & & & & & & & \\
\hline & eu & & & & & & & & & & \\
\hline
\end{tabular}

\section{REALIZACIONES CARACTERÍSTICAS DE LOS FONEMAS Q}

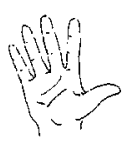

$\ddot{o}$

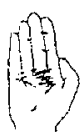

ò

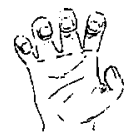

ó

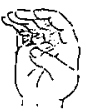

o’á

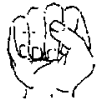

o

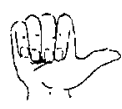

a

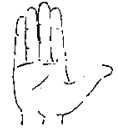

òa 


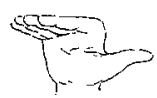

o'a

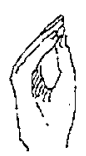

ô

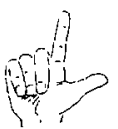

$\mathbf{a e}$

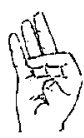

éá

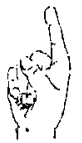

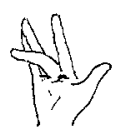

i

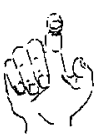

áé

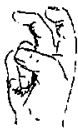

éí

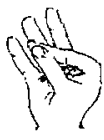

eâ

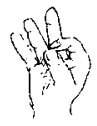

eä

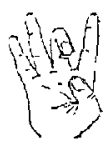

íá

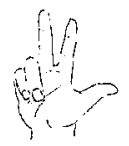

aei

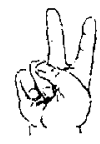

ei

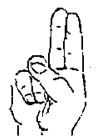

èi

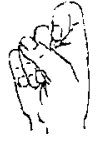

é

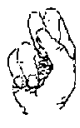

äei

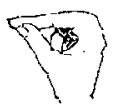

âe

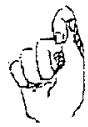

àé

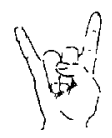

eu

Diseño de Dolores Baell

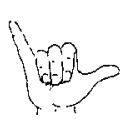

au

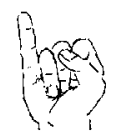

$\mathbf{u}$

El aspecto más importante del criterio alfabético que empleamos en nuestro sistema de escritura es que todos los tipos de fonemas (configuraciones Q, lugares Lf y $\mathrm{Ll}$, movimientos direccionales $\mathrm{M}$ y formas de movimiento $\mathrm{F}$ ) representan mediante vocales una proyección simple de la mano activa que señala en las configuraciones $\mathrm{Q}$ el dedo significativo y en el resto la ubicación o dirección que asociamos a cada uno de los dedos. Para entender esta proyección hay que imaginarse la mano en la posición natural lateral, con el canto en continuidad con brazo flexionado hacia el frente, y con la configuración que escribimos como i (con la que se signan limpio, amor..).

Las configuraciones con los símbolos a, e, i, y u representarán siempre configuraciones caracterizadas por el dedo pulgar (a), índice (e), corazón (i) y meñique (u); la configuración o representa siempre en la LSE la mano entera, ya sea extendida y de dedos separados (ö), juntos (ò), flexionados en sus dos formas (dedos separados ó, dedos juntos o'), o cerrados (mano en capullo ô y en puño o) 
En la posición natural de la mano y con la $Q$ en i, la dirección a que empleamos en movimientos direccionales $\mathrm{M}$ (wa, ca, etc.), en ubicaciones LI y Lf ( $a b$, al) y en orientaciones $\mathrm{O}$ ( $\mathrm{ma}$, mau, etc.) es la dirección hacia arriba que en esa posición señala el pulgar; la dirección e (we, etc.) la frontal; la i la lateral, la u hacia abajo y la o hacia el centro o signante; añadiremos la dirección y para la lateral derecha y la au para las diagonales.

Representamos por lo tanto con la e y la u las configuraciones de los dedos respectivos (índice, meñique) sobre la mano cerrada en puño; sin embargo, la i representa la configuración del corazón flexionado con la mano abierta, pues no hay en LSE configuración del corazón sobre el puño cerrado. Es esta una excepción que creemos justificada, pues la representación del resto de Q, L y O descansa en la proyección de esta configuración.

Para el conjunto del cuadro es importantísimo, además, distinguir el orden de los símbolos, por ejemplo éá frente a áé si la configuración empieza por a se trata de una configuración realizada con la mano cerrada en puño, del que emergen los dedos representados (en este caso el pulgar y el índice, flexionados); si empieza por e o i, la configuración se realiza a partir de la mano extendida (éá es la configuración con la palma extendida y los dedos pulgar e índice flexionados). Así pues, para la lectura hay que recordar que un núcleo que empieza con a indica necesariamente puño cerrado, el que empieza por otra vocal palma abierta.

Para distinguir el resto de configuraciones hay que tener en cuenta los símbolos diacríticos de dedos juntos ("), flexión ( ), dedos juntos y flexión ("), y los de contacto $(\wedge)$ y de enlace $\left({ }^{*}\right)$ que se representan sobre el símbolo simple o sobre la a de los símbolos múltiples

Como hemos señalado, las configuraciones dactilológicas y las numéricas, incluso aunque coincidan con alguna de las sistemáticas (Q) que hemos reflejado en el cuadro (como es el caso de o y «a», o de «dos» con ei) deben representarse de forma distinta, mediante la letra dactilológica en mayúscula (A, T, etc.) o mediante el número $(1,2$, etc.). Esto es importante tanto para la economía de la escritura como para su congruencia con el sistema y con los niveles de articulación (fonológico, morfológico). El resto de s-fonemas pueden combinar sus rasgos con estas configuraciones (signamos teoría con una «t», que escribimos $\mathrm{T}$, ante la frente y con cierto movimiento de giro; o repasar con una «r» $\mathrm{R}$ que gira sobre la palma izquierda rozándola; los números pueden integrarse en el signo de los verbos de movimiento y posición como morfemas de número, etc.). Las configuraciones dactilológicas más empleadas en la LSE como neologismos son: la T (como en teoria), la W (como en whisky), la $\mathrm{R}$ (como en reglas), la $\mathrm{J}$ (como en jefe), la $\mathrm{F}$ (como en Francia), la Z (como en Zamora) y la C (como en constitución). En cuanto a los números, deben representarse como tales $(1,2$, etc.) en sus valores 
cardinales (como en tres), ordinales (como en primero), o al incorporarse como morfemas de número a verbos.

A continuación damos dos ejemplos de cada configuración sistemática, que escribimos completamente en el Anexo

$\begin{array}{ll}\text { ö } & \text { seña-nombre. lengua de signos } \\ \text { ó } & \text { rey. enero } \\ \text { o } & \text { miércoles. torpe } \\ \text { o'a } & \text { adulto. mil } \\ \text { a } & \text { campeonato. sábado } \\ \text { iä } & \text { café. tontería } \\ \text { éá } & \text { real. elegir } \\ \text { eä } & \text { teatro. juicio } \\ \text { é } & \text { lógico. profesor } \\ \text { éí } & \text { buscar. morbo } \\ \text { ae } & \text { fácil. muy lejos } \\ \text { âe } & \text { enterar. punto de frase } \\ \text { u } & \text { poco. ojalá } \\ \text { àei } & \text { por. qué te importa } \\ \text { au } & \text { aeropuerto. demasiado }\end{array}$

$\begin{array}{ll}\text { ò } & \text { cara a cara. principal } \\ \hat{o} & \text { acuerdo. bobo } \\ \text { òa } & \text { universidad. martes } \\ \text { o'á } & \text { mesón. Cuba } \\ \text { i } & \text { contacto. contento } \\ \text { iá } & \text { médico. sinvergüenza } \\ \text { eâ } & \text { rorteo. estricto } \\ \text { e } & \text { decir. loco } \\ \text { ei } & \text { conocer. visual } \\ \text { èì } & \text { padre. madre } \\ \text { áé } & \text { persona. reunión } \\ \text { àé } & \text { comprar. contado } \\ \text { aei } & \text { Alicante. lujo } \\ \text { eu } & \text { teléfono. azul }\end{array}$

La selección de nuestros 29 fonemas Q de la LSE supone una distinción metodológica absolutamente irrenunciable en Lingüística: la de unidad y variante, s-fonema y s-alófono. Idealmente, la totalidad de las configuraciones efectivas que podemos encontrar deben ser variantes de esas unidades, que nos representamos por la variante más común o más distintiva. Así, aei representa la configuración de puño cerrado con pulgar, índice y corazón extendidos tanto si el índice y el corazón están en contacto como si están separados (lo que fonéticamente se representaría como aei vs. aèi). Para diferenciar unidades y variantes es necesario considerar los dos aspectos siguientes:

a) que las variantes lo sean en un marco fonológico general (que se describan con los mismos rasgos fonológicos distintivos de los fonemas, pues pueden ser fonemas en otro sistema)

b) que la selección de una variante se explique por reglas fonológicas. Las reglas fonológicas que permiten derivar variantes $\mathrm{Q}$ son como hemos señalado de dos tipos: contextuales o de influencia de otros fonemas próximos, de posición silábica, y, en las LSs, además, de adaptación icónica.

La especificación de variantes es por lo tanto la especificación de fonemas potenciales que en la lengua en cuestión, aquí la LSE, no se han sistematizado para diferenciar segmentos de enunciados. 
Vamos a señalar a continuación las variantes más frecuentes y significativas de algunos los $29 \mathrm{~s}$-fonemas Q que hemos propuesto. Con ellos debe darse una indicación de la regla de variación que la convierte en variante, sea una regla contextual, posicional, de adaptación icónica o de varios de estos tres tipos al mismo tiempo. En este trabajo sólo presentaremos algunos ejemplos significativos que ilustren el resto de las reducciones que hemos llevado a cabo. Nuestro propósito no es fonético, sino fonológico-escritural.

\section{Reducción de variantes}

Si las configuraciones, por ejemplo, la del «cuatro» o la del índice totalmente cerrado (ë) no figuran en nuestro cuadro de s-fonemas configurativos $Q$ es porque (incluso ante la evidencia de que se emplean) los consideramos variantes. Son estos casos no tan claros los que hay que explicar (¿por qué no se representan con signos propios, si tienen «letras» como òä y ë para hacerlo, y los signantes los signan de hecho?). Los trataremos a título de ejemplo ( reducción de ë a é, y de 4 a ö y ò) y trataremos luego otros en cierto modo inversos, de disimilación de lo que podría parecer muy similar.

La realización que representaríamos fonéticamente como ë y con la que se signan en la LSE bastantes palabras (duro, pistola, etc.) aparece como variante del s-fonema é por las siguientes reglas:

-por adaptación icónica instrumental, como en goma o pistola, en donde el dedo reproduce su empleo real.

-por influencia de otros fonemas en el mismo contexto, como duro, en donde el s-fonema F señala un golpe: una é más golpe se realiza como ë.

-por posición, al final de la sílaba tras una $F$ de flexión la configuración resultante promueve un incremento de la distintividad de la flexión del s-fonema é respecto de la extensión del s-fonema e: por ejemplo en preguntar, para diferenciarse de decir cuando el resto de fonemas son similares y se trata de dos actos de habla claramente distintos, preguntar debe terminarse con ë; pero la escritura no requiere señalar ese incremento de flexión, porque no es distintivo sino característico, y e y é se distinguen perfectamente. Lo mismo sucede con el doblete saber vs. recordar. En estos casos lo importante para el sistema fonológico es que ambas realizaciones no son distintivas; es más; la peculiar adaptación icónica de los signos manuales permite graduar la intensidad del acto concentrado en la signación de preguntar o de recordar y realizarlos con é.

- A veces el sentimiento de la diferencia entre é y ë se debe a razones de desambigüación de una homonimia, como en el par cómo vs. difícil (o el de dulce vs. dolor, para poner un ejemplo con otro queirema). La homonimia encierra acaso una relación semántica que no se nos escapa totalmente pero que no sabemos formular. En ambos casos el contexto y el tipo de acto discriminan, y a ellos 
contribuye la prosodia facial. Que difícil rubrique su signo con una expresión facial ilustrativa y con una configuración manual «difícil», tensa, excesiva, es además un mecanismo de adaptación icónica.

Así pues, el rasgo de «cierre» aplicado al índice no es distintivo respecto del rasgo «flexión». Es lo que sucede en la LSE en general con las configuraciones de dedos sin pulgar, o dicho de otro modo, sólo las que emplean activamente el pulgar recurren al rasgo de «cierre»: he aquí ya una restricción que vale como regla fonológica muy general. La realización de la variante ë se debe a reglas contextuales, de posición y de adaptación icónica.

La reducción de la realización del 4 en la de los fonemas ö y ò (con dedos juntos y separados) se ha decidido por un razonamiento similar. Al margen de los casos en los que con el 4 indicamos número (que es un morfema) dentro de los verbos de movimiento o posición, y de los empleos anagramáticos (como en Barcelona), en donde representamos el «4», encontramos:

-por adaptación icónica al referente, realizaciones « $4 »$ de $\ddot{0}$, en pestañas, en bingo, barandilla, desfile, alinear, etc.

-por influencia contextual, encontramos numerosas realizaciones «4» de ò. Así, por influencia del s-fonema $\mathrm{F}$ de rozamiento $(\mathrm{z})$ sobre la configuración ò como en sucio, jueves, etc.; o de giro (wr) como en cambiar de idea, acontecimiento, etc.; o del s-fonema $\mathrm{C}$ de contacto (.) como en enfadado, mesa, gorra, psicología, esconderse, etc., en todos estos casos esa configuración se realiza con el pulgar abatido, en «4». Lo mismo sucede por la influencia sobre la configuración ò del sfonema de movimiento lineal (w) como en fax, bajar/subir un coche una cuesta, guardar, etc.; o del de diapasón (d) como en calle. Si el signo es bimanual (jueves, mesa, psicología), ò se realiza también como «4» si el contacto o el rozamiento entre las manos se realiza de canto con palma hacia abajo (lo que se representa en la escritura mediante la orientación $\mathrm{O}$ meu).También se hace «4» el ö bimanual con $\mathrm{s}$-fonema de movimiento con rozamiento $(\mathrm{z})$ de las manos por la palma activa como en tejer, o de $\mathrm{F}$ de punteo (pointing) (p) como en estructura. Todos estos s-fonemas influyen sobre las configuraciones $Q \ddot{O}$ y ò y las llevan a una variación característica. Pero no serían signos distintos los signados (a pesar de la incomodidad articulatoria) con la configuración característica del fonema.

-por posición al final de sílaba también otras configuraciones experimentan variación en «4»; así, si al núcleo ô le sigue un s-fonema $\mathrm{F}$ de movimiento de extensión sucesiva de dedos (ls), entonces la extensión de la coda del signo se realiza como 4 de dedos abiertos (como en edificio, algunos, etc.) Se trata de una regla contextual posicional: realización de ô más $\mathrm{F}$ (ls) al final del signo. 


\section{Disimilación de variantes}

Veamos ahora casos contrarios: dos queiremas que podrían considerarse, como los anteriores, variantes, que de hecho pueden neutralizarse y que, sin embargo, proponemos como queiremas. El primero de ellos es el fonema de configuración o'a que distinguimos de o'á - y naturalmente de ó y de óa. La configuración òa es distintiva en signos como martes, inteligente..., aunque con mucha frecuencia es variante de ò: si hay prevista flexión de la palma en ò, esta $Q$ se realiza con pulgar extendido, como òa, para que la $\mathrm{F}$ de flexión la reduzca a o'a y no a o' (que no es distintivo); esta regla explica numerosas realizaciones más: cerveza, mantequilla, no hay, echar, pedir.. Del mismo modo, si hay movimiento direccional diagonal (au) la configuración ò se hace òa, pues es el pulgar el que orienta el movimiento, como en adjetivo; lo mismo ocurre si hay $\mathrm{F}$ de golpe (x) como en pegar, estudiar, o movimiento de fricción circular (wr) como en placer. En la escritura consideraremos estas variantes como casos de neutralización entre ò y òa (las escribimos con ò). Pero hay signos donde la elección es necesaria, como sucede en signos como hola que signamos con ò o con signos como inteligente, que signamos con òa. Del mismo modo, mantenemos la oposición entre ò y o'a porque a pesar de poderse entender a veces como adaptaciones icónicas hay otros casos en los que son claramente distintivos: menos vs parada, descuento vs despacio, entrar vs marcharse, llenar vs enfadarse, archivo vs librería, etc. Sin duda estamos ante algo distintivo.

El que una configuración sea distintiva no significa que pierda su iconismo: lo restringe a los límites de su distintividad. De hecho hay signos en los que ò parece icónica, y lo es: naipes, seguramente pared, techo, cúpula, etc. Pero el iconismo (o su sentimiento) se pierde en otros muchos. En otros actúa de forma más abstracta, como clasificador. Sin duda el iconismo contribuye a su significado, pero este último es ya gramatical. En todo caso el criterio para la asignación de unidades es la propia economía del sistema, que establece entre sus unidades correlaciones de mayor o menor rendimiento. Una de las ventajas del sistema de escritura que proponemos es que, por su carácter fonológico, hace evidentes muchas de las correlaciones que el sistema explota, como por ejemplo

$\begin{array}{lcc}\text { íá } & \text { iâa } & \text { iä } \\ \text { éá } & \text { eâ } & \text { eä } \\ \text { áé } & \text { (âe) } & \text { äe }\end{array}$

que podemos formar por la presencia de un rasgo tan productivo como el de contacto vs. enlace de pulgar. O las que podríamos formar por la incidencia del rasgo (-pulgar): e / ae, u/ au, etc. 
Fonemas y alófonos pertenecen al mismo sistema de diferencias, y entran en el mismo conjunto de correlaciones. No hay pues infinitas variantes (no hay una variante de «t» sonora en castellano, como no hay variante de «i LSE - y existiendo la eu, la razón no puede ser el tabú). Además, las variantes deben explicarse por reglas fonológicas. Las que hemos encontrado en la LSE son del mismo tipo que las de las LOs: por influencia de otros fonemas contiguos (velarización por velar, extensión del pulgar por movimiento), y por posición silábica (consonantes trabantes 1 y $\mathrm{r}$, variantes por extensión o cierre). Además, hemos encontrado un recurso a lo que llamamos adaptación icónica, que permite al signante un gran margen de variación. Confiamos en que los ejemplos anteriores sea suficientemente ilustrativos para los fines de este trabajo. Las diferencias fonológicas señaladas y los casos de variación fonológica son aplicables a muchas otras configuraciones de la LSE. Dejamos para trabajos posteriores la especificación de la variantes más frecuentes de cada fonema configurativo.

\section{Los s-fonemas de Lugar ( Lc, Lf y Ll) y de Contacto (C)}

Comenzamos a escribir los signos por los s-fonemas de Lugar, como ya hemos explicado. El lugar puede ser el cuerpo (Lc), el espacio frontal del signante (Lf) y el lugar lateral natural al signante (Ll). El contacto $\mathrm{C}$ sólo se da en el Lc, y admite sólo dos posibilidades: contacto, en cuyo caso el Lc se escribe sin solución de continuidad con Q (LQ: por ejemplo ka, para la mano en puño con el pulgar extendido tocando de forma natural la mejilla, es decir, orientando la palma hacia la mejilla), o no contacto (el signo se realiza frente al lugar señalado sin tocarlo) en cuyo caso se signa el lugar seguido de punto y de Q (Lc.Q, por ejemplo c.e: la configuración de índice erguido que se realiza frente a la cabeza ).

El cuerpo como lugar de signación Lc debe señalarse (por tratarse de un continuum) de forma anagramática. Las soluciones de división del cuerpo en cuatro o cinco zonas abstractas no nos parecen basadas en la semiótica de las LSs. Hemos decidido suplir algunas iniciales del español repetidas o poco comunes con las del inglés o francés, si están figurativa o dactilológicamente motivadas (como la barbilla por «ch», o la sien por «t»). Proponemos la siguiente representación (a los elementos ubicados a la derecha de un lugar con centro se les añade una «m», y a los de la izquierda una «n»). Los ejemplos están escritos en el Anexo.

$\begin{array}{lll}\text { 1.cabeza } & \mathrm{c} & \text { indio. principal } \\ \text { 2.frente } & \mathrm{f} & \text { harto. torpe } \\ \text { 3.sien } & \mathrm{t} & \text { loco. pueblo } \\ \text { 4.entrecejo } & \mathrm{jz} & \text { venganza. antiguo } \\ \text { 5.ojos } & \mathrm{j} & \text { cuidado. ojo } \\ \text { 6.comisura ojos } & \mathrm{jm} & \text { atención. síndrome de Down }\end{array}$




$\begin{array}{lll}\text { 7.oreja } & \mathrm{r} & \text { sordo. hipoacúsico } \\ \text { 8.nariz } & \mathrm{z} & \text { oso. huele } \\ \text { 9.mejilla } & \mathrm{k} & \text { cariño. embarazada } \\ \text { 10.mandíbula } & \mathrm{kh} & \text { fácil. guapo } \\ \text { 11.bigote } & \mathrm{zV} & \text { gato. bigote } \\ \text { 12.boca } & \mathrm{v} & \text { paciencia. rojo } \\ \text { 13.comisuras } & \mathrm{vm} & \text { sonrisa. galleta } \\ \text { 14.dientes } & \mathrm{d} & \text { envidia. cristal } \\ \text { 15.labio inferior } & \mathrm{chv} & \text { dolor. cómo } \\ \text { 16.mentón } & \mathrm{ch} & \text { aviso. enfadado } \\ \text { 17.submentón } & \mathrm{sch} & \text { demasiado. algo } \\ \text { 18.garganta } & \mathrm{th} & \text { vicio. ganas } \\ \text { 19.cuello } & \mathrm{q} & \text { asco. ahorcar } \\ \text { 20.hombros } & \mathrm{hm} & \text { judo. ayer } \\ \text { 21.axilas } & \mathrm{xm} & \text { termómetro. universidad } \\ \text { 22.clavículas } & \mathrm{pn} & \text { premio. blanco } \\ \text { 23.pecho centro } & \mathrm{y} & \text { lo siento. identidad } \\ \text { 24. pecho lateral } & \mathrm{yn} & \text { lástima. malo } \\ \text { 25.estómago } & \mathrm{st} & \text { encantar. estómago } \\ \text { 26.cintura } & \tilde{\mathrm{n}} & \text { criada. Ibiza } \\ \text { 27.pierna } & \mathrm{g} & \text { medias. jamón } \\ \text { 28.muñeza izqda } & \mathrm{sah} & \text { guía. enfermo } \\ \text { 29.brazo izqdo } & \mathrm{br} & \text { inyección. Cruz Roja } \\ \text { 30.codo izqdo. } & \text { soh } & \text { pobre. Último } \\ \end{array}$

Además, como hemos indicado, señalamos con una s la mano izquierda como Lc acompañada de las especificaciones de $\mathrm{L}$ y $\mathrm{O}$ si es necesario.

Distinguimos del Lc otros dos espacios: el lugar frontal al signante (Lf), que a veces se llama la pizarra de la signación y que en los diestros ocupa fundamentalmente la parte frontal izquierda, y el lugar natural, con el brazo en su lado (LI); los representaremos en el ataque silábico, como todo fonema de lugar, mediante los símbolos -1 y $-\mathrm{b}$, respectivamente.

En estos espacios lo que escribimos es la ubicación del brazo anteponiendo a los símbolos $-\mathrm{l}$ y $-\mathrm{b}$ los de las vocales correspondientes al esquema de proyección en i, que, como señalábamos páginas atrás, es un esquema fundamental para la economía de nuestro sistema de escritura: hacia arriba (al, ab), hacia el frente (el, eb), hacia el lado izquierdo (il), hacia el centro (ol, ob), hacia abajo (ul, ub) y, con menos sistematismo, hacia el lado derecho ( $\mathrm{yb}$ ) y en la diagonal (au). Aunque es especialmente importante a la hora de estudiar la semiótica del espacio signado distinguir signos realizados en el Ll y en el Lf (como verdad frente a correcto; 
mandar frente a tú; este frente a aquel; o de acuerdo frente a no hacer caso), el centro de Lf (ol) y el lateral de Ll (ib) pueden coincidir. Suprimimos este último por razones de economía, aunque no podemos dejar de señalar esta significativa identificación del centro del signante con el lateral de la signación. Pero hay que distinguir cuidadosamente el centro de $\mathrm{Ll}$, que se realiza introduciendo un poco el codo hasta dejar la mano a la altura del estómago (ob). Razones similares llevan a la supresión de el por identificación con el signo, aunque con frecuencia se realiza la posición el como resultado de ob+we.

Las distintas ubicaciones y direcciones geométricamente posibles ni tienen la misma posibilidad de realizarse ni reflejan la necesaria (por natural) asimetría de la mano activa. Los esquemas geométricos tienen en este sentido demasiados símbolos y adolecen de iconismo ingenuo: geometrizar las ubicaciones no es suficiente, pues la geometría de la mano debe ser sensible a la falta de su simetría y de la articulación del brazo, que es la base de sus empleos semióticos. De ahí que las direcciones a la derecha, por ejemplo, o las diagonales, sean muy escasamente sistemáticas. Con todo mantenemos aún su representación hasta que nuevos datos aconsejen o no su reducción por economía.

A continuación damos ejemplos de las once ubicaciones más frecuentes en Lf y Ll, ejemplos que escribimos en el Anexo:

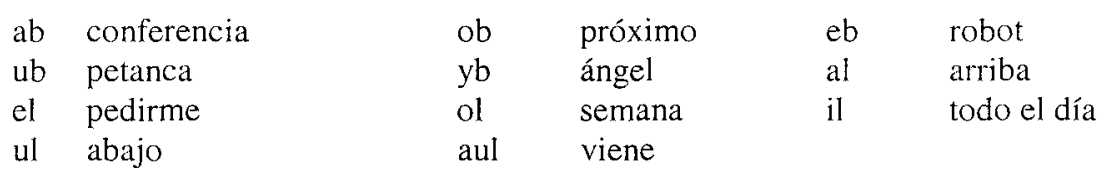

\section{Las Orientaciones}

La mano (que representamos con una m para la mano derecha antes de anotar su orientación, cuando esta orientación es distintiva, y con una s para la izquierda) puede estar orientada con el canto hacia arriba (en continuidad con el brazo si éste está flexionado: $\mathrm{ma}, \mathrm{sa}$ ), hacia el frente (brazo abatido: me, se), hacia abajo (brazo suelto: mu, su) y hacia el lado (brazo flexionado lateralmente: mi, si); raramente hacia el lado izquierdo, siempre con el brazo flexionado (my). En esas posiciones, que se representan, como hemos dicho y aplicado ya a los Lf y $\mathrm{Ll}$, por el esquema de proyección de la mano en i, la mano puede además estar de canto en continuidad natural (es lo que representamos con los símbolos anteriores: ma, mi) o puede tener la palma hacia el signante en posición frontal o hacia arriba en la posición natural de brazo flexionado (se añade una a) o hacia el receptor o hacia abajo (se añade una $u$ ), o -más raramente, es verdad - hacia el lado derecho del signante (se añade una y). Son posibles por lo tanto las siguientes orientaciones de la mano 
activa, que representaremos inmediatamente después de la configuración Q (los ejemplos se escriben en el Anexo):

$\begin{array}{lllllr}\text { ma } & \text { pintura. no hay } & \text { maa } & \text { pasado. exposición } & \text { mau } & \text { frente. pintor } \\ \text { me } & \text { hospital. pequeño } & \text { mea } & \text { importante. animar } & \text { meu igualdad.baja } \\ \text { mi } & \text { próximo. futuro } & \text { mia } & \text { invitar. ensalada } & \text { miu estatuto.participar } \\ \text { mu } & \text { carretera. maleta } & \text { mua } & \text { último. calle } & \text { muu torero. bolos } \\ \text { my } & \text { persona } & \text { mya } & \text { camarero } & \text { myu ángel } \\ \text { may } & \text { lado derecho } & \text { mey } & \text { apartar.perder } & \text { miy centro.suspender } \\ \text { muy } & \text { pelo largo } & \text { mo } & \text { responsable } & \end{array}$

La economía de la escritura aconseja no representar ubicaciones y orientaciones cuando ofrezcan una información redundante. Ya hemos dado algunas de las reglas más importantes de simplificación, y en ellas decíamos que había orientaciones naturales (la palma hacia el Lc, o de canto en continuidad con el brazo en Lf y Ll). Un Lc evita muchas veces la $\mathrm{O}$, por ser natural, y muchas veces la ubicación en los otros dos lugares de signación se supone señalando la orientación: ma --o maa, mau, por ejemplo, escritas tras un Q inicial de signo, indican que el brazo está flexionado «hacia arriba»; de lo contrario habría que escribir antes de la $O$ la ubicación $\mathrm{L}$ por posición del brazo (como en olQma); del mismo modo mi, mia, miu, indican tras una $Q$ inicial de signo que el brazo está flexionado al lado, pues si no lo está hay que reflejarlo (por ejemplo en ebQmi); y así sucesivamente. Este criterio tiene un gran poder de simplificación. A su vez, es innecesaria la orientación totalmente natural (ebQme) que no hay que escribir (por eso «tú" es simplemente e, la configuración del índice en su posición natural), aunque naturalmente hay que hacerlo en otras orientaciones como mea o meu. En cuanto al Lc, pensemos en la cantidad de signos de pensamiento (saber, pensar, recordar, etc.) cuya representación se simplifica al estar sistemática y significativamente orientados hacia la cabeza.

\section{Los Movimientos direccionales $M$}

Tomando de nuevo el esquema de proyección de la mano en su configuración i y en su posición natural (en Ll y con la mano de canto en continuidad con el brazo, es decir, hacia el frente) señalaremos las direcciones con a (arriba), e (frente), i (lado izquierdo), o (centro o signante), u (abajo), y (lado derecho), au (diagonal), precedidas de la indicación simbólica del tipo de movimiento direccional: de $w$ (movimiento recto: wa, we, etc.), de c (movimiento curvo: ca, cy, etc.), de $z$ (movimiento con rozamiento: za, zi, etc.), de p (punteo: hacia la derecha py, hacia abajo pu, etc), o de zp (roces puntuales realizados necesariamente en cierta dirección: zpa, zpe, etc.) Aprovecharemos algunos de estos símbolos para los movimientos sin dirección o Formas de movimiento. Damos a continuación 
ejemplos de los movimientos direccionales (que hay que escribir en la coda larga, como hemos indicado y como puede leerse en el Anexo) de la LSE:

$\begin{array}{llllll}\text { wa salvar. autoestima } & \text { we } & \text { pedir. permiso } & \text { wi } & \text { pequeño. oeste } \\ \text { wo fin. mirarme } & \text { wu } & \text { importante } & \text { wy } & \text { semana .mesa } \\ \text { wua } & \text { venir. tormenta } & \text { ca } & \text { superior } & \text { ce } & \text { puente-fiesta } \\ \text { ci aterrizaje } & \text { co } & \text { mi turno } & \text { cu } & \text { descender(clasif) } \\ \text { cy dar turno } & \text { cua } & \text { montaña } & \text { za } & \text { desarrollo } \\ \text { ze derrota } & \text { zy } & \text { querer } & \text { zo } & \text { perdón } \\ \text { zu cariño } & \text { zi } & \text { atropellar } & \text { zau } & \text { adjetivo } \\ \text { pa semáforo } & \text { pi } & \text { Badajoz } & \text { py } & \text { particular } \\ \text { pu embarazada. } & \text { zpa } & \text { lástima } & \text { zpe } & \text { chivato } \\ \text { zpu sábado } & \text { zpi } & \text { octubre } & \text { zpy } & \text { Hamburgo }\end{array}$

La única excepción a este criterio de representación la constituyen los casos en los que la configuración $\mathrm{Q}$ toca sucesivamente en dos lugares del cuerpo, como en madre, sordo, etc., en cuyo caso se señala como Lc el primero y como $\mathrm{M}$ el segundo.

\section{Las formas de movimiento}

Sin duda se trata de la clase fonemas más intuitiva y peor definida pero, al mismo tiempo, una de las más recurrentes. Su intenso carácter icónico adquiere en los procesos de gramaticalización un grado de abstracción muy notable, pero no es objetivo de este artículo entrar ahora en esos procesos. Nosotros la definimos como clase mociones de la mano sobre alguno de sus ejes (muñeca a, nudillos de los dedos e, codo o, hombro u) o en relación con el Lugar de signación. Así pues, las vocales representan en los fonemas Q a los dedos; en los Lf, Ll, O y M las ubicaciones correspondientes a los mismos dedos en el esquema proyección de la mano en i; y en los F, además, las articulaciones .

Las Formas de movimiento no son movimientos lineales de desplazamiento (rectos o curvos), sino giros (que representamos al final del signo con una wr: wra, wro, wru ); semigiros de $90^{\circ}$ (tipo llave: ro hacia la izquierda o signante, re hacia la derecha o receptor) o de $180^{\mathrm{a}}$ (fre, fro); abatimientos (fa de la mano por la muñeca, fo del brazo por el hombro, fe del dedo); oscilaciones de tipo diapasón (da, do, du); punteo (p); golpe (x); temblor (t); extensión o cierre de Q (1), y extensión o cierre de dedos sucesivos (ls); movimiento de dedos alternos $(\mathrm{s})$; coger $(\mathrm{g})$ y repetición (b). El roce y el punteo pueden darse como movimientos direccionales, como hemos visto. $Y$ como también se ha señalado, la coda está formada muy frecuentemente por combinación de $\mathrm{M}$ y $\mathrm{F}$. Damos ejemplos de las más significativas formas de movimiento, cuyos símbolos se escriben al final del signo (el último siempre el de repetición b) como puede verse en el Anexo: 


$\begin{array}{llllll}\text { wra } & \text { serpiente } & \text { wro } & \text { solo } & \text { wru } & \text { lengua de signos } \\ \text { fa puerta } & \text { fe } & \text { pintura } & \text { fo } & \text { vencer } \\ \text { da no } & \text { do } & \text { pegar } & \text { du } & \text { mecer } \\ \text { X dinero al contado } & \text { re } & \text { llave } & \text { ro } & \text { cerrado } \\ \text { fre intérprete } & \text { fro } & \text { responder } & \text { g } & \text { mujer. piel } \\ \text { t } & \text { duda. terremoto } & \text { l } & \text { conferencia } & \text { ls } & \text { robar. cuántos } \\ \text { s } & \text { problemas. andar } & \text { p } & \text { broma } & \text { b } & \text { hierro. broma }\end{array}$

\section{Signos bimanuales}

La mano pasiva (normalmente la izquierda) es muy frecuentemente un lugar de signación, pero a diferencia de los otros Lc la mano pasiva puede ubicarse en su Lf y L1, puede articularse en un Q y puede orientarse. Simbolizamos la mano pasiva con una s, precedida de su L si es distintivo y seguida de su Q, nueva s y su O. La sílaba pasiva LsQsO se escribe al comienzo (pues es el Lc de la mano activa) separado de los fonemas de la mano activa por un espacio en blanco. Como Lc, la mano pasiva puede recibir las $\mathrm{F}$ de la mano activa, como en calidad, centro de ciudad (véase el vocabulario del Anexo); o ser sólo el lugar de referencia, como en marcharse.

Pero además, la mano pasiva puede simultanear simétrica o antisimétricamente el signo que realiza la mano activa. Representaremos estos signos bimanuales mediante una $s$ inicial seguida de las siguiente consonantes que son de hecho Formas de movimiento y un espacio antes de los fonemas de la mano activa:

sm para el movimiento simétrico y exento de las dos manos (como en siempre, responsable)

sl para el movimiento alternativo de las dos manos (como en teatro, comparar)

sh para el movimiento contiguo de las dos manos (como en persigue, atasco)

sg para el enlazarse de las dos manos (como amigo, unidos)

sc para el movimiento antisimétrico de las dos manos desde el contacto (como en divorcio, mesa)

ss para el movimiento de las manos juntas (como en acompañar, techo)

sz para el rozarse (de forma alternativa) de las dos manos (como en lengua de signos, cotilleo)

sx para el golpearse de las dos manos (como en hierro, junto)

sp para el puntear de una mano con la otra (como en casa, tío)

Pueden leerse estos ejemplos escritos en al Anexo.

Como hemos apuntado, la escritura de las derivaciones morfológicas y de los distintos tipos de elocución puede requerir la incorporación de algún signo nuevo, pero nos atrevemos a adelantar que será en numero reducidísimo y que, por el contrario, será en la sistematización gramatical donde el estudio de los registros escritos puede dar mayores beneficios a la investigación y a la plena normalización 
de las LSs. La escritura refleja la economía de las lenguas y garantiza su difusión, pero además, como hemos sugerido, produce un registro de la lengua que ante todo se caracteriza por la sistematización de las estructuras gramaticales. Anexo. Vocabulario citado.

\begin{tabular}{|c|c|}
\hline abajo & ulemuawu \\
\hline acompañar & ss ômeawe \\
\hline acontecimiento & alòmaro \\
\hline acuerdo & sx ôma \\
\hline adjetivo & pnòmiazau \\
\hline adulto & o'aweb \\
\hline aeropuerto & abaumeuwe \\
\hline ahorcar & q.cämix \\
\hline alejarse & taewel \\
\hline algo & sch.o'azpeb \\
\hline algunos & omauls \\
\hline Alicante & kaeimaufeb \\
\hline alinear & söse ömezo \\
\hline amigo & sg o'ameudob \\
\hline amor & ynimix \\
\hline ángel & sm òmyufab \\
\hline animar & sl ömeawrob \\
\hline anormal & emaudab sm eämerob \\
\hline antiguo & jz.épb \\
\hline aparte & òmeywy \\
\hline apuntarse & sòsau emiux \\
\hline aquel & abemeuweb \\
\hline archivar & so'asi o'amiacob \\
\hline arriba & alemawab \\
\hline asco & qömou \\
\hline atasco & sh òmeuceb \\
\hline atención & sm jmòwe \\
\hline aterrizaje & sòsiu abaumiuwauzi \\
\hline atropellar & stòmiazi \\
\hline autoestima & stóamawaz \\
\hline aviso & chémace \\
\hline ayer & hm.òafax \\
\hline azul & k. euzpro \\
\hline Badajoz & q.âepi \\
\hline baja-enfermedad & òmeuwu \\
\hline bajar un coche & alòmiuwau \\
\hline barandilla & sc ömauwub \\
\hline Barcelona & sōsi 4mauzpu \\
\hline bigote & zvemiuwy \\
\hline bingo & sp ömiub \\
\hline blanco & pniäwel \\
\hline bobo & k.ôpb \\
\hline bolos & òmuuwul \\
\hline broma & ch.òpb \\
\hline
\end{tabular}

\begin{tabular}{|c|c|}
\hline buscar & jz.éímauwru \\
\hline café & v.iälb \\
\hline calidad & sòsa iämilxb \\
\hline calle & sòsi òmuadab \\
\hline camarero & abömyawro \\
\hline cambio de idea & tòwere \\
\hline campeonato & sl amewub \\
\hline campo & sosi ömeuxb \\
\hline cara-a-cara & zòwe \\
\hline cariño & kòzub \\
\hline carretera & sm òmudab \\
\hline casa & sp òmab \\
\hline centro-cuidad & sòasia amiypb \\
\hline cerrado & àémero \\
\hline cerveza & sosi òmizpeb \\
\hline coger & elöwol \\
\hline comba & àémewro \\
\hline cómo & chv.émapb? \\
\hline comparar & sl òmaaweb \\
\hline comprar & sòsi àézpu \\
\hline condenar & òmada \\
\hline conferencia & abowelb \\
\hline conocer-persona & sp eimab \\
\hline constitución & sòsau Cmapub \\
\hline contacto-persona & sp ib \\
\hline contado-dinero & sòsea àćx \\
\hline contento & k.ipb \\
\hline correcto & oleämewy \\
\hline costumbre & k.ezpu \\
\hline cotilleo & sz cmeuweb \\
\hline criada & sm ñòmeapb \\
\hline cristal & a.épb \\
\hline cruz roja & breiwewy \\
\hline cuando-futuro & abòmiwru \\
\hline cuando-pasado & abòmaafab \\
\hline Cuba & kho’ázi \\
\hline cuentas & omaals \\
\hline cuidado & jeweeäfo \\
\hline cúpula & sc alòmeuwyre \\
\hline chivato & sch.özpeb \\
\hline de acuerdo & sm ömafa \\
\hline decir & ch.epb \\
\hline demasiado & sch.aux \\
\hline derrota & sòsea ömeuze \\
\hline
\end{tabular}




\begin{tabular}{|c|c|c|c|}
\hline desarrollo & sòsiu emeuza & hipoacúsico & r.o'azpe \\
\hline descenso-clasificar & sc amaucub & hola & tòwe \\
\hline descuento & o'amawu & hospital & sm aeimepy \\
\hline desfile & sh ömuafob & huele & z.epb \\
\hline despacio & sm òmeuwub & Ibiza & sm ñòameuwy \\
\hline difícil & chv.émapb & idea & t.iäl \\
\hline director & sl emeudob & identidad & y.aumapb \\
\hline divorcio & sc ameure & igualdad & sp òmeub \\
\hline olor & chvemiuzy & importante & òmeawub \\
\hline dolor & chvemiuzy & incidente & sl ömeuwru \\
\hline dormir & kò & indio & cäeiwal \\
\hline duda & sòsia ómiut & inteligente & tòamauwyl \\
\hline dulce & chvemiuzy & intérprete & sòsia eimeufre \\
\hline duro & sòsi émezpu & invitar & sh òmiawe \\
\hline echar & sea òamauro & inyección & br.aeipl \\
\hline edificio & sm omiwals & jamón & g.òmuarox \\
\hline elegir & eléáwal & jefe & abJmauwro \\
\hline embarazada & k.amapu & judo & sh hmomada \\
\hline encantar-conocer & stòwru & jueves & sz òmeuweb \\
\hline enero & f.ópb & juicio & sl eämewub \\
\hline enfadado & ch.òmiupb & junto & sx òme \\
\hline enfermo & sah.íámeupb & lástima & y.òzpab \\
\hline cnsalada & sl ömiawru & lengua-de-Signos & sz ömawru \\
\hline enterar & jmâemaufr & librería & sòsia òmezpib sòsi àézpu \\
\hline entrar & so'asia òwe & limpio & kizub \\
\hline envidia & démoig & loco & tet \\
\hline esconderse & sh òmadob & lógico & ch.épb \\
\hline estatuto & sòsau òmiupub & lo-siento & sm yöce \\
\hline estómago & st.ipb & lujo & kaeiwuz \\
\hline estricto & teâwe & llave & àémereb \\
\hline estructura & sösi ömiwopb & llenar & scho' amiux \\
\hline estudiar & sx òmaa & madre & knèikm \\
\hline excursión & pmame obòwaufeb & maleta & omuwab \\
\hline exposición & sc òmaapyb & malo & yn.ipb \\
\hline fácil & khaezel & mandar & abedo \\
\hline fax & sòsiu òmeuzpe & mantequilla & sòsia òmezofrzeb \\
\hline fin & sm aeimauwol & marcharse & sòsi òce \\
\hline Francia & Fmaro & martes & $\mathrm{sx}$ òamiuxb \\
\hline frente & òmauwe & mecer & sh.òmiadub \\
\hline galleta & vmáémipb & medias & sm göza \\
\hline ganas & th.òafezpb & médico & sah. íapb \\
\hline gato & zy.âemas & menos & abo'ameuwu \\
\hline goma & sp émib & mentira & k.emauzpe \\
\hline gorra & fòmiuwuwe & mesa & sc òmeuwy \\
\hline guapo & kh.òazpelx & mesón & kho'ázib \\
\hline guardar & sòsiu òmeuze & miércoles & sl ymowuzb \\
\hline guía & sahíámeuwe & $\mathrm{mil}$ & sòse o'amip \\
\hline Hamburgo & j.aemazpyl & mirarme & j.eimouwo \\
\hline harto & formawe & montaña & sc alómiucaub \\
\hline hierro & sx omab & morbo & zéit \\
\hline
\end{tabular}




\begin{tabular}{|c|c|c|c|}
\hline muerto & y.ômiux & psicología & sòasa alòmepb \\
\hline mujer & ràég & pueblo & t.özpeb \\
\hline muy lejos & kaewro & puente-fiesta & olòmace \\
\hline naipe & sòsiu àémifab & puerta & sc òmifab \\
\hline no & emaudab & punto-frase & âemaup \\
\hline no hace caso & sòsi omeufab & querer & ynòmizy \\
\hline no-hay & òmafab & que-te-importa & zâeiwywel \\
\hline octubre & ch.òmiuzpib & real & kméág \\
\hline oeste & amauwi & recordar & tewel \\
\hline ójala & umaawro & reglas & sòsau Rmapub \\
\hline ojo & j.epb & repasar & sòsia Rmeuwroxb \\
\hline OSO & z.eäwru & responsable & sm pm.òamop \\
\hline paciencia & vamizub & reunión & sl áéwi \\
\hline padre & fèich & rey & c. $6 x$ \\
\hline padre-madre & fèìch knèikm & robar & ömals \\
\hline pagar & sòsia àémexb & robot & ebòmewab \\
\hline parada & sm òmeuwu & rojo & v.efezpb \\
\hline pared & ss òmiwa & sábado & k.azpub \\
\hline particular & yn.amaupy & saber & t.ero \\
\hline pasillo-puerta-lado & òmayce & salvar & sl ömauwafro \\
\hline pedir & òmeawe & semana & olameuwy \\
\hline pegar & òmeadob & seña-nombre & sch.öpb \\
\hline pelo largo & sm r.ömuydab & serpiente & emeuwra \\
\hline pequeño & sl òmewib & siempre & sm eämewru \\
\hline perdón & sòseu òmiuzob & síndrome-Down & jm.Szpyb \\
\hline perdón-lástima & yniwero & sin-vergüenza & kmkníáwe \\
\hline permiso & vòwe & solo & emaawro \\
\hline persigue & sh amewet & sonrisa & vmemifeb \\
\hline persona & abáémywu & sordo & rech \\
\hline personal & áémiawu & sorteo & so'áse eâmeufr \\
\hline pestaña & jöwe & subir un coche & olòmiuwau \\
\hline petanca & ubómaawel & sucio & k.òzpeb \\
\hline piel & kàég & superior & abo'aca \\
\hline pintor & òmaufab & suspender ex. & amiywu \\
\hline pintura & eimauwufeb & teatro & sl ym.eämiuweb \\
\hline piso & omire wy & techo & ss alòmiuwe \\
\hline pistola & elb & tejer & sz ömeuwes \\
\hline placer & stòwru & teléfono & reu \\
\hline pobre & sohózy & teoría & f.Tmawru \\
\hline poco & ch.umoupb & termómetro & xnemo \\
\hline por & âeil & terremoto & sm ömeut \\
\hline porro & k.òxb & tío & sp émab \\
\hline pregunta & chewel & todo-el-día & sasec ameucy \\
\hline premio & pmeämax & tontería & t.iälb \\
\hline preocupar & feimius & torero & òmuuwo \\
\hline primero & ablre & tormeta & sausec auwuadab \\
\hline principal & c.òpb & torpe & f.oxb \\
\hline principal & c.òpb & traidor & Sòasi eumiurox \\
\hline profesor & t.émauzpeb & tres $(3)$ & 3 mauwru \\
\hline próximo & òmiwe & turno-a-mí & eleimacox \\
\hline
\end{tabular}




$\begin{array}{llll}\text { turno-persona } & \text { ileimacyb } & \text { ver } & \text { jeimeuwe } \\ \text { último } & \text { soh.aropb } & \text { verdad } & \text { eämewub } \\ \text { unidos } & \text { sg eädob } & \text { vicio } & \text { hezu } \\ \text { universidad } & \text { xn.òapb } & \text { viene } & \text { auláwau } \\ \text { vacaciones } & \text { sm xmömius } & \text { visual } & \text { sl eiweb } \\ \text { vencer } & \text { abomaufo } & \text { whisky } & \text { ebWmauda } \\ \text { venganza-recordar } & \text { jzémax } & \text { Zamora } & \text { Zmeuwyb } \\ \text { venir } & \text { aléímawua } & & \end{array}$

\section{Referencias bibliográficas:}

Chomsky, Noam (1995): «Language and Nature», Mind 104, págs.1-60. Versión española en Una aproximación naturalista a la mente y al lenguaje. Barcelona, editorial Prensa Ibérica, 1998, págs.161-192

Bolinger, Dwight (1983): «Intonation and Gesture», American Speech 58, págs. 156-174

Brentari, Diane (1998): A prosodic Model of Sign Language Phonology. Chicago, BradfordBook.

Deuchar, Margaret (1987): «Sign Language Research», Lyons, John (ed) NewHorizonts in Linguistics, 2. London, Pinguin, págs.311-335.

Givón, Talmy (1998): «The syntax of literacy», Syntaxis 1, págs.1-40.

Herrero, Ángel (1986): «Gestos, silencio y lenguaje. Límites de la abducción verbal», Actas del III Congreso de Lingüística Aplicada, Córdoba, págs. 232251

Herrero, Ángel (1998): «La seña y el signo. Notas sobre iconicidad en la LSE», Cifuentes, J. L. (ed) Estudios de Lingüística Cognitiva I, Alicante, Universidad, págs. 207-225

Hulst, Harry va der (1993): «Units in the análisis of sings», Phonology 10/2, págs.209-242.

Jackendoff Ray (1987): Consciousness and the computational mind, Massachusetts Institute of Technology. Traducción española La conciencia y la mente computacional, Madrid, Visor, 1998.

Jakobson, Roman y Halle, Morris (1952): Preliminaries to speech analysis. Cambridge, MIT Press.

Jakobson y Halle (1956): Fundamentals of Language. Ed. esp. Fundamentos del lenguaje, Madrid, Ayuso, 1974.

Juncos, Onésimo; Camaño, Andrés; Justo, $M^{a}$ José et alii (1997): «Primeras palabras en la Lengua de Signos Española (LSE). Estructura formal, semántica y contextual», Revista de Logopedia, Foniatría y Audiología, XVII, $\mathrm{n}^{\mathrm{o}} 3$, págs.170-181 
Liddell, Scott y Johnson, Robert (1989): «American Sign Language: The Phonological Base», Sign Language Studies 64, págs. 195-277

Marr, David (1982): Vision. San Francisco, CA., Freeman

Muñoz Baell, Irma (1999): ¿Cómo se articula la LSE?, Madrid, CNSE

Pinedo Peydró, Félix-Jesús (1989): «Métodos Sutton Sign Writing (Escritura de signos Sutton) y «SignFont» (Fuente de signos). Comparación entre ambos sistemas».

Pinedo Peydró, Félix Jesús (1989b): Una voz para el Silencio. Madrid, Fomento de Empleo para Minusválidos SL., págs. 191-210

Prillwitz, Siegmund y Vollhaber, Tomas (eds.) (1991): Sign Language research and application. Proceedings of the International Congress on Sign Language Research and Application. International Studies on Sign Language and Communication of the Deaf, 13, Hamburgo, Signum, págs.275-294

Rodríguez González M.Ángeles (1992): Lenguaje de Signos. Barcelona. Confederación Nacional de Sordos de España y Fundación ONCE

Sutton, Valerie y Gleves, Richard (1995): SignWriter Computer Program Version 4.3, La Jolla, The Deaf Action Committee For SignWriting

Wilbur, Ronnie (1990): «Why Syllables? What the Notion Means for ASL Research», Fisher, S y Siple, P. (eds.) Theoretical isuues in Sign Language Research, Chicago, University Press, págs. 81-108 